\title{
Disease detection and resource use in the safety and control arms of the HPV FOCAL cervical cancer screening trial
}

Andrew J Coldman ${ }^{\star}{ }^{1}$, Lovedeep Gondara ${ }^{1}$, Laurie W Smith ${ }^{1}$, Dirk van Niekerk ${ }^{2}$, Kathy Ceballos ${ }^{2}$, Mel Krajden ${ }^{3}$, Darrel Cook ${ }^{1}$, David J Quinlan ${ }^{4}$, Marette Lee ${ }^{4}$, Gavin CE Stuart ${ }^{4}$, Stuart Peacock ${ }^{5}$, Ruth Elwood Martin ${ }^{6}$, Laura Gentile ${ }^{2}$, Eduardo L Franco ${ }^{7}$ and Gina S Ogilvie ${ }^{6,8}$

${ }^{1}$ Cancer Control Research, BC Cancer Research Centre, 675W 10th Ave, Vancouver, British Columbia, V5Z 1 L3 Canada; ${ }^{2}$ Cervical Cancer Screening Program, BC Cancer Agency, 650W 10th Ave, Vancouver, British Columbia, V5Z 4E6 Canada; ${ }^{3}$ Clinical Prevention Services, BC Centre for Disease Control, 655W 12th Ave, Vancouver, British Columbia, V5Z 4R4 Canada; ${ }^{4}$ Department of Obstetrics and Gynecology, University of British Columbia, 1190 Hornby Street, Vancouver, British Columbia, V6Z 2K5 Canada; ${ }^{5}$ Canadian Centre for Applied Research in Cancer Control, BC Cancer Research Centre, 675W 10th Ave, Vancouver, British Columbia, V5Z 1 L3 Canada; ${ }^{6}$ School of Public Health, University of British Columbia, 2206 E Mall, Vancouver, British Columbia, V6T $1 Z 9$ Canada; 'Division of Cancer Epidemiology, McGill University, 546 Pine Ave West, Montreal, Quebec, H2W 1S6 Canada and ${ }^{8}$ Women's Health Research Institute, Women's Hospital, Vancouver, British Columbia, V6H 3N1 Canada

Background: The HPV FOCAL Trial is a RCT comparing human papilloma virus (HPV) with Liquid Based Cytology (LBC) screening for cervical cancer. Results are presented for the comparison of the Safety and Control arms after two rounds.

Methods: HPV FOCAL included randomisation of women aged 25-65 into the Safety arm, where they were initially screened with HPV and the Control arm, where they received entry screening with LBC, with both arms screened again with LBC at 24 months.

Results: There are 6203 (Safety) and 6075 (Control) women included in this analysis. For the Safety vs Control arms, Round 1 screening resulted in increased detection of cervical intraepithelial neoplasia 2 or worse (CIN2 +), 15.3 vs 10.4 per 1000, RR $=1.48$ $(95 \% \mathrm{Cl}=1.08-2.03)$ and higher colposcopy referral rates, 5.6\% vs 3.2\%. LBC screening at 24 months resulted in similar colposcopy referral rates, $1.5 \%$ vs $1.9 \%$, and decreased CIN2 + detection, 2.0 vs 4.7 per $1000, \mathrm{RR}=0.43(95 \% \mathrm{Cl}=0.21-0.88)$ in the Safety vs Control arms. CIN2 + detection and colposcopy referral rates declined with increasing age in both arms. One round of HPV screening detected similar levels of CIN2 + as two rounds of LBC screening.

Interpretation: CIN2 + detection at 2 years was lower in those screened by HPV, indicating an improved 2-year negative predictive value of the HPV test.

Testing for high-risk human papillomaviruses (HPV) has been proposed for primary screening for prevention of cervical cancer via the detection of its precursors (Sasieni and Cuzick, 2002; Cuzick et al, 2008; Franceschi et al, 2011; Murphy et al, 2011; Arbyn et al, 2012; Ronco et al, 2012; Wright et al, 2012). HPV testing is recognised as being more sensitive than cytology for the detection of high-grade cervical intraepithelial neoplasia (CIN) grade 2 or more severe (CIN2+) (Cuzick et al, 2006; Mayrand et al, 2007), although with lower specificity. HPV testing also has a higher negative predictive value at 60 months for cervical intraepithelial neoplasia grade 3 or more severe $(\mathrm{CIN} 3+)$ than cytology at 24 months (van den Akker-van Marie et al, 2003;

*Correspondence: Dr A Coldman; E-mail: acoldman@bccrc.ca

Received 17 June 2016; revised 6 October 2016; accepted 17 October 2016; published online 17 November 2016

(c) 2016 Cancer Research UK. All rights reserved 0007-0920/16 
Dillner et al, 2008). Comparison of HPV vs cytology screening in randomised trials has resulted in considerable evidence supporting the use of HPV-based testing for increased detection of CIN2 + at initial screening and reduced subsequent risks of cervical cancer and its precursors (Naucler et al, 2007; Kitchener et al, 2009; Arbyn et al, 2012; Leinonen et al, 2012; Rijkaart et al, 2012a; Ronco et al, 2014). These findings have resulted in the scheduled adoption of primary HPV-based screening strategies in some countries (Health Council of the Netherlands, 2011; Australian Government, 2014).

The HPV testing for Cervical Cancer Screening Trial (HPV FOCAL) (Ogilvie et al, 2010, 2012) is a Canadian randomised clinical trial (RCT) comparing primary HPV testing with Liquid Based Cytology (LBC) for cervical cancer screening. Women were randomized into one of the three arms: Intervention, Control or Safety (Figure 1) (Ogilvie et al, 2010). Women in the Intervention and Safety arms received primary HPV testing with cytology triage at entry. Women in the Control arm received primary LBC testing at entry and at 24 months. Women in the Safety arm received LBC screening at 24 months and exited the study. Women in the Intervention and Control arms receive co-testing with HPV and LBC at 48 months and exited the study.

The Safety arm was included in HPV FOCAL to provide an early indication of the safety of extending to a 48-month screening interval as used in the Intervention arm because a 24-month interval was the community standard. The trial protocol specified that the Safety and Control arms were to be compared, on cervical intraepithelial neoplasia grade 2 or worse $(\mathrm{CIN} 2+)$, at specified thresholds of subjects completing the 24-month screening round with a view to potential early stopping of the trial. This manuscript reports rates of disease detection, and resource utilisation of the final protocol specified comparison of the Safety and Control arms when accrual to the Safety arm was complete. Future reports will present results comparing the Intervention and Control arms over 48 months, when that the data is complete as specified in the protocol.

\section{MATERIALS AND METHODS}

Over 25000 British Columbia women between the ages of 25 and 65 were randomised within HPV FOCAL (ISRCTN79347302). All women in HPV FOCAL were participants in the British Columbia Cervical Cancer Screening Program (CCSP) and patients of collaborating family physicians (Ogilvie et al, 2010). Study participants were required to not be pregnant, not have been screened within the previous 12 months, have no history of CIN2 + in the preceding 5 years and provide informed consent (Ogilvie et al, 2012).

Randomisation to the three study arms, Intervention, Control and Safety (Figure 1), was made with equal probability until 1 January 2011, when the planned sample size for the Safety arm (6200) was achieved. Thereafter, randomisation occurred equally to the Intervention and Control arms until the planned sample size for these arms was attained. Simple randomisation with equal probabilities of one-third were used to create a single assignment list to the three trial arms and subjects were allocated sequentially based upon the accession of their specimen at the central laboratory. Subjects and their physicians were blinded to their allocation until 24 months, unless follow-up of an abnormal test was required and they were then informed of the test used. Trial testing in the Control and Safety arms at baseline and at 24 months was as follows:

Control arm. Women received LBC testing at Baseline and those negative for intraepithelial lesion or malignancy (NILM) were recalled for LBC screening again at 24 months. Those with lowgrade squamous intraepithelial lesion or worse ( $\geqslant$ LSIL) were recommended for colposcopy. Those with atypical squamous cells undetermined significance (ASCUS) were triaged with an HPV test, and if positive were recommended for colposcopy and if negative were recalled at 12 months and retested with LBC. Those ASCUS or greater ( $\geqslant$ ASCUS) were recommended for colposcopy and those NILM were returned to screening with LBC

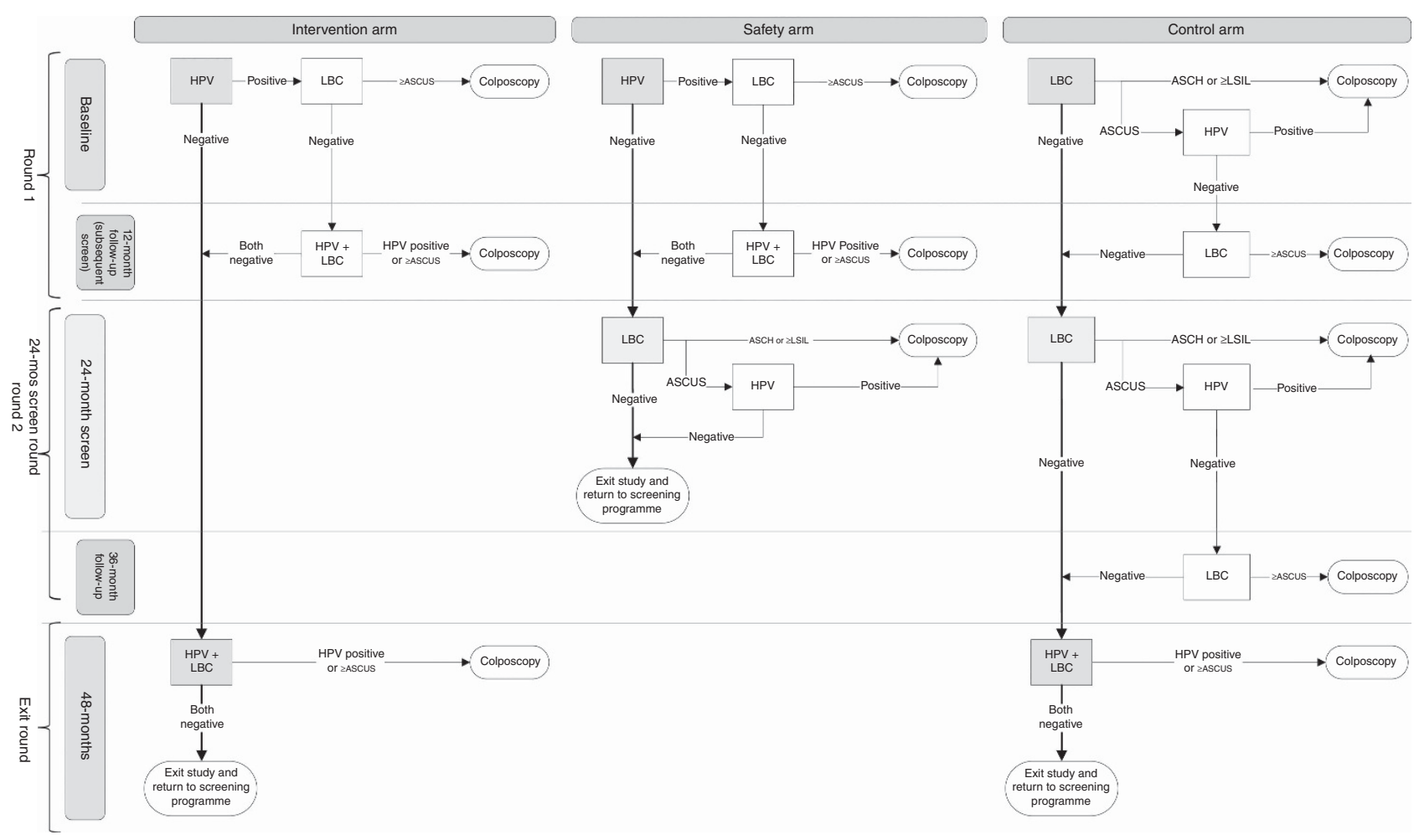

Figure 1. HPV FOCAL study schematic. Subjects with unsatisfactory cytology were retested and if persistent (3 consecutive) were referred to colposcopy. 
at 24 months. Screening at 24 months used the same management scheme as at baseline (Figure 1).

Safety arm. Women received HPV testing at Baseline and those testing negative were recalled for exit screening with LBC at 24 months. Those Baseline HPV positive were triaged with LBC and those $\geqslant$ ASCUS were recommended for colposcopy. Those with cytology triage of NILM were recalled 12 months later for HPV and LBC co-testing and recommended for colposcopy if HPV positive and/or $\geqslant$ ASCUS; those both LBC and HPV negative were returned to screening and recalled for LBC at 24 months for their final screen. LBC screening at 24 months used the same management scheme as in the Control arm (Figure 1) except that women ASCUS and HPV negative were retested 12 months later through the CCSP using conventional cytology.

If a woman, in any arm, had CIN2 + diagnosed, she exited the trial and future screening was directed by her family physician. If a woman had CIN1 or negative results at colposcopy, she was returned to HPV FOCAL screening within her randomisation group.

Trial participants had samples collected using the ThinPrep (Hologic Ltd, Toronto, ON, Canada) sample-processing protocol and screen and triage tests were performed on the same collected

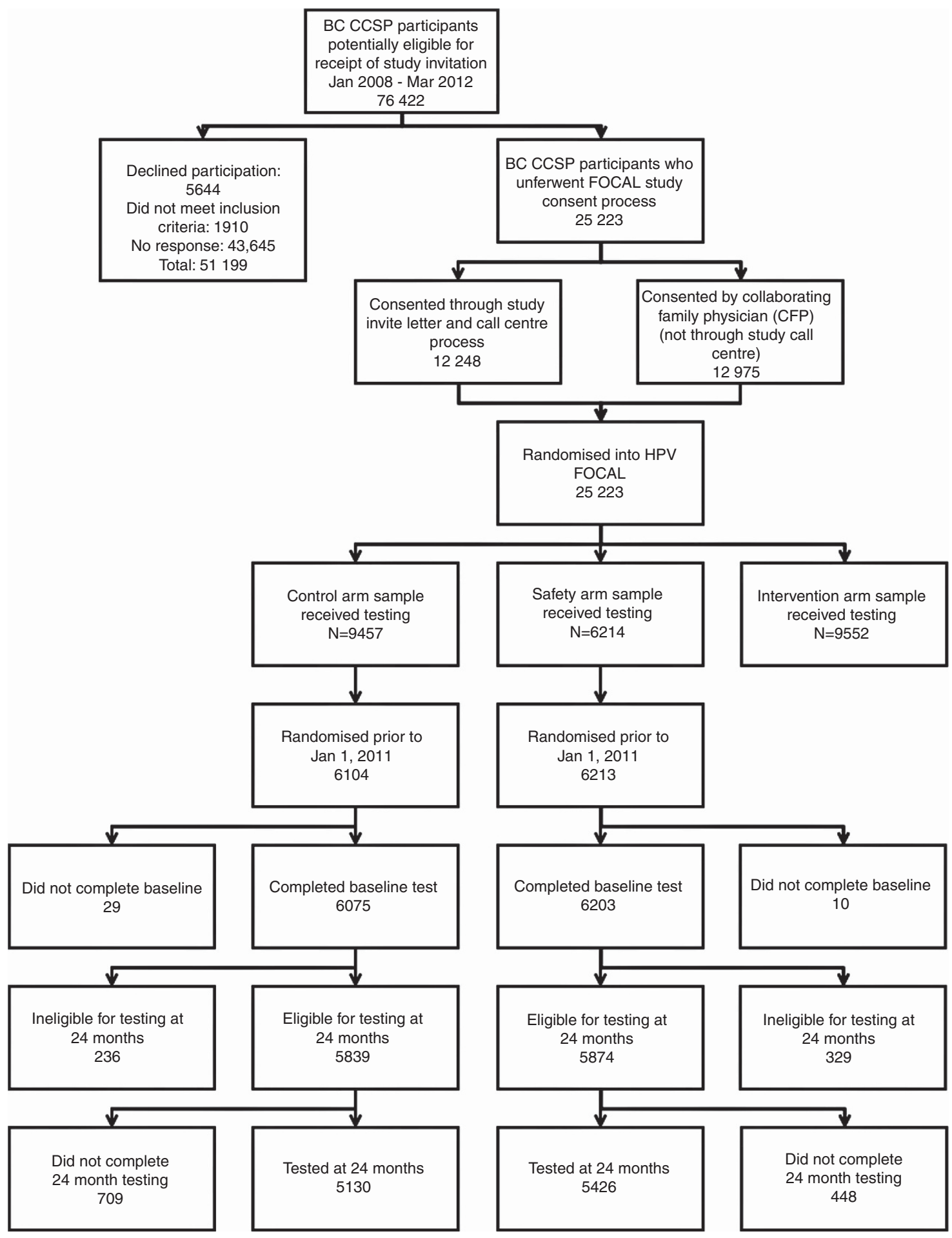

Figure 2. Consort diagram for the HPV FOCAL Safety and Control arms for testing at Baseline and at 24 months. 
specimen. The HPV testing was performed using Digene Hybrid Capture 2 (HC2) high-risk HPV DNA Test (Qiagen Inc., Toronto, $\mathrm{ON}$, Canada) and women high-risk $\mathrm{HPV}$ positive $(\mathrm{HPV}+)$ received triage by LBC (Cook et al, 2015).

The data were extracted for the two screening rounds, at entry and 24-months, for all women randomised to the Control and Safety arms prior to 1 January 2011. The rates of referral for colposcopy and CIN detected at Round 1 (Baseline and 12-month follow-up, if required), 24-month screen round (including 36month follow-up, if required) and cumulatively for the two arms were calculated. Overall and age-specific rates are presented. Cumulative rates of CIN2 + and CIN3 + are reported based upon randomisation arm and on an intention-to-treat basis. Test results are reported as proportions based upon subjects undergoing testing. Significance tests were performed using the $\chi^{2}$ test for count data. Confidence intervals were based on the binomial distribution. Test of significance for odds ratios and confidence intervals was calculated using the asymptotic distribution of the log odds ratio (Breslow and Day, 1980).

The Safety arm was included in HPV FOCAL to monitor the early effect of the extended 4-year interval in the Intervention arm. By design, it was specified that comparison of the Safety and Control arms should be undertaken before accrual was complete to the trial. The trial protocol indicated that CIN2 + detection from LBC testing at 24 months in the Safety arm should be $<80 \%$ of that observed in the Control arm. A formal group sequential analysis plan using Pocock boundaries (DeMets and Lan, 1995) was used in which the rate of CIN2 + detection at 2 years was compared between the Safety and Control arms at pre-specified numbers of Safety arm subjects completing the 24-month screening round $(500,1000,1500,2500$ and 6200) using a standardised test statistic specified in the study protocol. The distribution of disease and resource use at the final analysis are presented.

This research was approved by Research Ethics Board of the University of British Columbia, BC Cancer Agency branch, approval number H06-04032.

\section{RESULTS}

There were 6213 and 6104 women randomised to the Safety and Control arms prior to 1 January 2011, of which 6203 and 6075 , respectively, had a satisfactory baseline screen. Figure 2 provides a consort diagram for subject accrual to the study. Randomisation to the two arms achieved balance by age when coded by decade $(P=0.13)$, self-reported ethnicity in 6 categories $(P=0.95)$, education level in 4 levels $(P=0.90)$ and lifetime sexual partners in 4 categories $(P=0.41)$. The age at randomisation distribution was <30: 8.1\%, 30-39: 23.9\%, 40-49: $32.6 \%$ and $50+$ : $35.4 \%$.

The results of Round 1 screening are given in Table 1. For baseline testing, the rate of $\geqslant$ ASCUS in the Control arm was 3.8 per $100(95 \% \mathrm{CI}=3.3-4.3)$ and the rate of $\mathrm{HPV}+/ \geqslant$ ASCUS in the Safety arm was 2.8 per $100(95 \% \mathrm{CI}=2.4-3.3)$. The amount of triage testing was higher in the Safety arm: $8.4 \%$ of women required reflex LBC testing in the Safety arm for a positive HPV result compared with $1.0 \%$ who required reflex HPV testing in the Control arm for an ASCUS result. Follow-up testing of subjects at 12 months was also more common in the Safety arm (5.2\%) than in the Control arm (0.7\%). Overall, more colposcopies were performed in Round 1 in the Safety arm (5.6\%) than in the Control arm (3.2\%). Twelve month follow-up testing resulted in the identification of more disease overall in Round 1 in the Safety arm than in the Control arm, with detection rates of $15.3(95 / 6203)$ per 1000 vs $10.4(63 / 6075)$ per $1000, \mathrm{RR}=1.48(95 \% \mathrm{CI}=1.08-2.03)$ for $\geqslant$ CIN2 and $6.9(43 / 6203)$ per 1000 vs $4.6(28 / 6075)$ per 1000 $(\mathrm{RR}=1.50,95 \% \mathrm{CI}=0.94-2.42)$ for $\mathrm{CIN} 3+$. These are similar to Round 1 results already reported for the trial where the data from the Intervention arm are included (Ogilvie et al, 2012). The number of colposcopies per CIN2 + identified was higher in the Safety arm, 3.7, (95\% CI =3.1-4.4) than in the Control arm 3.1, $(95 \% \mathrm{CI}=2.6-3.9)$, although this difference was not significant $(P=0.23)$.

\section{Table 1. Round 1 test results, referral to colposcopy and pathology findings for the safety and control arms}

\begin{tabular}{|c|c|c|c|c|c|}
\hline $\begin{array}{l}\text { Round } 1 \\
\text { Screening Category }\end{array}$ & Category & \multicolumn{2}{|c|}{ Safety arm } & \multicolumn{2}{|c|}{ Control arm } \\
\hline \multirow{3}{*}{ Baseline testing } & Completed testing & & 6203 & 6075 & \\
\hline & Test result & $\mathrm{HPV}+$ & $519(8.4)$ & $\begin{array}{l}167(2.7) \\
62(1.0)\end{array}$ & $\begin{array}{l}\geqslant \text { LSIL } \\
\text { ASCUS }\end{array}$ \\
\hline & $\begin{array}{l}\text { Colposcopy with biopsy performed } \\
\text { CIN2 }+ \\
\text { CIN3 }+\end{array}$ & & $\begin{array}{c}169 \\
52(0.84) \\
25(0.40)\end{array}$ & $\begin{array}{c}187 \\
62(1.02) \\
28(0.46)\end{array}$ & \\
\hline \multirow[t]{2}{*}{12 month follow-up testing } & Eligible & Baseline HPV + /NILM & 343 & 42 & Baseline ASCUS/HPV - \\
\hline & $\begin{array}{l}\text { Colposcopy with biopsy performed } \\
\text { CIN2 }+ \\
\text { CIN3 }+\end{array}$ & & $\begin{array}{c}178 \\
43(13) \\
18(5.6) \\
\end{array}$ & $\begin{array}{c}8 \\
1(2.5) \\
0 \\
\end{array}$ & \\
\hline Round 1 overall & $\begin{array}{l}\text { Colposcopies performed } \\
\text { CIN2 } \\
\text { CIN3 }+\end{array}$ & & $\begin{array}{c}347 \\
95(1.53) \\
43(0.69)\end{array}$ & $\begin{array}{c}195 \\
63(1.04) \\
28(0.46)\end{array}$ & \\
\hline
\end{tabular}


Table 2. Results of LBC testing at the 24-month screen round in the safety and control arms

\begin{tabular}{|c|c|c|c|}
\hline 24-month round & Category & Safety arm (\%) & Control arm (\%) \\
\hline & Number eligible for testing ${ }^{a}$ & 5874 & 5839 \\
\hline LBC testing at 24 months & $\begin{array}{l}\text { Completed testing } \\
\text { Screening result } \\
\geqslant \text { LSIL } \\
\text { ASCUS/HPV + } \\
\text { Unsatisfactory cytology } \\
\text { Referred to colposcopy } \\
\text { Colposcopy and biopsy } \\
\text { CIN2 }+ \\
\text { CIN3 }+\end{array}$ & $\begin{array}{c}5426 \\
67(1.2) \\
6 \\
6 \\
79(1.5) \\
78 \\
11(0.20) \\
3(0.06)\end{array}$ & $\begin{array}{c}5130 \\
77(1.5) \\
20 \\
2 \\
99(1.9) \\
95 \\
24(0.46) \\
13(0.25)\end{array}$ \\
\hline 36-month follow-up testing. & $\begin{array}{l}\text { Eligible for follow-up testing } \\
\text { Referred to colposcopy } \\
\text { ₹ASCUS } \\
\text { Attended colposcopy w Biopsy } \\
\text { CIN2 + } \\
\text { CIN3 + }\end{array}$ & $\begin{array}{l}32 \\
2 \\
1 \\
0 \\
0\end{array}$ & $\begin{array}{l}29 \\
2 \\
2 \\
0 \\
0\end{array}$ \\
\hline Total for 24-month screening round & $\begin{array}{l}\text { Overall Refer to Colposcopy } \\
\text { Colposcopy Performed w biopsy } \\
\text { CIN2 }+ \\
\text { CIN3 }+\end{array}$ & $\begin{array}{l}81(1.5) \\
79 \\
11(0.20) \\
3(0.06)\end{array}$ & $\begin{array}{l}101(2.0) \\
97 \\
24(0.47) \\
13(0.25)\end{array}$ \\
\hline
\end{tabular}

The results of the 24-month round of screening (including 36month follow-up results) are given in Table 2 . Women who did not have CIN2 + identified in either Safety or Control arms at the first round and who had not withdrawn or become ineligible (e.g., had hysterectomy or emigrated from British Columbia) were eligible for rescreening at 24 months. There were 5874 and 5839 not known to be ineligible for rescreening in the Safety and Control arms at 24 months and $5426(92.3 \%)$ and 5130 (87.9\%), respectively, who returned for screening; $P<0.001$ for difference in testing rates. No CIN2 + was detected at the 36-month follow-up test in the 24month round. Among those tested, colposcopy was slightly more frequent in the Control arm, 19 per $1000(95 \% \mathrm{CI}=16-23)$, than in the Safety arm, 15 per $1000(95 \% \mathrm{CI}=12-18)$, with $P=0.08$ for difference. Less disease was identified in the Safety arm than in the Control arm at the 24-month screening round and the detection rates were 2.0 per 1000 vs 4.7 per $1000, \mathrm{RR}=0.43(95 \% \mathrm{CI}=0.21-$ $0.88)$, and 0.6 per 1000 vs 2.5 per $1000, \mathrm{RR}=0.22(95 \% \mathrm{CI}=0.06-$ 0.77 ) for CIN2 + and CIN $3+$, respectively. The ratio of CIN2 + detection at the 24-month round in the Safety arm compared with the Control arm was $43 \%$, which met the threshold of $<80 \%$ specified in the HPV FOCAL trial protocol. In both arms, rates were higher in Round 1 than in the 24-month round for CIN2 + and $\mathrm{CIN} 3+$ : Safety arm $\mathrm{RR}=7.6(95 \% \mathrm{CI}=4.1-14.1)$ and Control arm $\mathrm{RR}=2.2(95 \% \mathrm{CI}=1.4-3.6)$ for $\mathrm{CIN} 2+$.

Table 3 provides summary results on the disease detection by age at entry, screening round and study arm. Generally, the Safety arm had higher rates of detection at the initial round than the Control arm, although confidence intervals, especially for CIN3 +, were generally quite wide, and for the 30-34-year-age-group, the observed difference went in the opposite direction. The rates of detected disease declined with increasing age in both arms in Round 1 and in the 24-month screen rounds (Table 3 ).

To anticipate the relative performance of HPV screening, every 4 years $v s$ LBC screening every 2 years, results from Round 1 testing in the Safety arm can be compared with the sum of Round 1 plus 24-month results from the Control arm. The cumulative rates of disease detection for the combined Round 1 and 24-month screening round results for the Control arm were similar to the Round 1 rates in the Safety arm (Table 3). For all ages combined, the odds ratio of disease detection for first round Safety arm vs both rounds of the Control arm were $\mathrm{RR}=1.07$ (95\% $\mathrm{CI}=0.80$ $1.43)$ and $\mathrm{RR}=1.03(95 \% \mathrm{CI}=0.67-1.57)$ for $\mathrm{CIN} 2+$ and $\mathrm{CIN} 3+$, respectively. Excluding the youngest age-group (25-29 years) did not substantially alter the relationship with $\mathrm{RR}=1.04$ $(95 \% \mathrm{CI}=0.73-1.47)$ and $\mathrm{RR}=0.92(95 \% \mathrm{CI}=0.54-1.56)$ for $\mathrm{CIN} 2+$ and $\mathrm{CIN} 3+$, respectively.

Table 4 provides age-specific rates of specimen collection, test performance and colposcopy for Round 1 in the Safety arm, and combined Round 1 and 24-month screening round in the Control arm. In Table 4, a screening test and a resulting triage test is counted as one specimen and two tests. Overall, the likelihood of referral to colposcopy was higher in the Safety arm than in the Control arm, $\mathrm{RR}=1.17(95 \% \mathrm{CI}=1.00-1.38)$. In subjects over 30 years of age, the increase in referral to colposcopy was not significant $\quad \mathrm{RR}=1.05 \quad(95 \% \quad \mathrm{CI}=0.87-1.26)$, whereas it was significant in those under 30 years of age $R R=1.60 \quad(95 \%$ $\mathrm{CI}=1.14-2.24)$. Numbers of screening specimens and tests performed were higher in the Control arm than in the Safety arm overall, and for each of the age groups. The magnitude of the difference was smallest for the youngest group (age 25-29 years) and increased with age.

\section{DISCUSSION}

These results illustrate that higher rates of both $\mathrm{CIN} 2+$ and CIN3 + were detected at Round 1 screening in the Safety arm, where screening was HPV based, compared with the Control arm, where screening was LBC based. Cumulative disease detection from the combined Round 1 and 24-month screening round in the Control arm was similar to that of Round 1 in the Safety arm. Disease detection in age subgroups was consistent with the preceding findings, although confidence intervals were wide. Cumulative referral to colposcopy at Round 1 and 24-month screening round for the Control arm was approximately equal to that of Round 1 for the Safety arm, indicating that overall referral to colposcopy would be similar for 2-year LBC screening and every 4 -year screening using HPV. The exception to this was the youngest group enrolled (25-29 years) where referral to colposcopy was significantly elevated for the Safety arm. Results presented show the HPV FOCAL trial met the protocol-specified target for CIN2 + detection in the Safety arm vs Control arm $(<80 \%)$ at 2 years with a relative rate of $43 \%$ observed. As anticipated, the need for testing and specimen collection was lower in the Safety arm than in the Control arm, indicating the potential for resource savings in all age groups. 
Table 3. Number of women randomised, cases of disease and rates of disease detection, with confidence intervals, for Round 1 and Round 1 plus 24-month round by age group at randomisation

\begin{tabular}{|c|c|c|c|c|c|c|}
\hline \multirow[b]{2}{*}{ Age at entry } & \multirow[b]{2}{*}{ Period } & \multirow[b]{2}{*}{ Outcome } & \multicolumn{4}{|c|}{ Study arm } \\
\hline & & & Count & Rate/1000 (95\%Cl) & Count & Rate/1000 (95\%Cl) \\
\hline \multirow{2}{*}{$25-29$} & Round 1 & $\begin{array}{l}\mathrm{CIN} 2+ \\
\mathrm{CIN} 3+\end{array}$ & $\begin{array}{l}32 \\
17\end{array}$ & $\begin{array}{l}61(43,85) \\
32(20,52)\end{array}$ & $\begin{array}{l}19 \\
10\end{array}$ & $\begin{array}{l}40(25,62) \\
21(11,39)\end{array}$ \\
\hline & Cumulative after two rounds & $\begin{array}{l}\text { CIN2 + } \\
\text { CIN3 + }\end{array}$ & $\begin{array}{l}35 \\
18\end{array}$ & $\begin{array}{l}67(48,92) \\
34(21,54)\end{array}$ & $\begin{array}{l}27 \\
13\end{array}$ & $\begin{array}{l}57(39,82) \\
27(16,47)\end{array}$ \\
\hline \multirow[t]{3}{*}{$30-34$} & & Total & 570 & & 630 & \\
\hline & Round 1 & $\begin{array}{l}\mathrm{CIN} 2+ \\
\mathrm{CIN} 3+\end{array}$ & $\begin{array}{c}16 \\
8\end{array}$ & $\begin{array}{c}28(17,45) \\
14(7,28)\end{array}$ & $\begin{array}{c}21 \\
9\end{array}$ & $\begin{array}{c}33(22,51) \\
14(7,27)\end{array}$ \\
\hline & Cumulative after two rounds & $\begin{array}{l}\mathrm{CIN} 2+ \\
\mathrm{CIN} 3+\end{array}$ & $\begin{array}{c}17 \\
8\end{array}$ & $\begin{array}{c}30(18,48) \\
14(7,28)\end{array}$ & $\begin{array}{l}26 \\
11\end{array}$ & $\begin{array}{c}41(28,60) \\
17(9,31)\end{array}$ \\
\hline $35-39$ & & Total & 895 & & 835 & \\
\hline \multirow[t]{3}{*}{$40-49$} & & Total & 2033 & & 1974 & \\
\hline & Round 1 & $\begin{array}{l}\mathrm{CIN} 2+ \\
\mathrm{CIN} 3+\end{array}$ & $\begin{array}{c}23 \\
8\end{array}$ & $\begin{array}{c}11(7,17) \\
4(2,8)\end{array}$ & $\begin{array}{c}12 \\
5\end{array}$ & $\begin{array}{c}6(3,11) \\
3(1,6)\end{array}$ \\
\hline & Cumulative after two rounds & $\begin{array}{l}\text { CIN2 + } \\
\text { CIN3 }+\end{array}$ & $\begin{array}{c}27 \\
9\end{array}$ & $\begin{array}{c}13(9,19) \\
4(2,9)\end{array}$ & $\begin{array}{c}16 \\
8\end{array}$ & $\begin{array}{c}8(5,13) \\
4(2,8)\end{array}$ \\
\hline \multirow[t]{3}{*}{$50-65$} & & Total & 2181 & & 2162 & \\
\hline & Round 1 & $\begin{array}{l}\mathrm{CIN} 2+ \\
\mathrm{CIN} 3+\end{array}$ & $\begin{array}{l}9 \\
4\end{array}$ & $\begin{array}{l}4(2,8) \\
2(1,5)\end{array}$ & $\begin{array}{l}5 \\
1\end{array}$ & $\begin{array}{c}2(1,6) \\
0.5(0,3)\end{array}$ \\
\hline & Cumulative after two rounds & $\begin{array}{l}\mathrm{CIN} 2+ \\
\mathrm{CIN} 3+\end{array}$ & $\begin{array}{c}10 \\
5\end{array}$ & $\begin{array}{l}5(2,8) \\
2(1,6)\end{array}$ & $\begin{array}{l}9 \\
4\end{array}$ & $\begin{array}{l}4(2,8) \\
2(1,5)\end{array}$ \\
\hline All & & Total & 6203 & & 6075 & \\
\hline
\end{tabular}

Table 4. Mean rates, with $95 \%$ Confidence Intervals, of specimen collection, tests and colposcopies performed as a result of Round 1 in the Safety arm and for combined Round 1 and 24-month round testing in the Control arm by age at study entry

\begin{tabular}{|l|c|c|c|c|c|c|c|}
\cline { 2 - 6 } & \multicolumn{2}{c}{$\begin{array}{c}\text { Mean specimens collected } \\
\text { per woman }\end{array}$} & \multicolumn{2}{c|}{$\begin{array}{c}\text { Mean tests performed } \\
\text { per woman }\end{array}$} & $\begin{array}{c}\text { Mean colposcopies performed } \\
\text { per } 100 \text { women }\end{array}$ \\
\hline Age at Entry & Safety & Control & Safety & Control & Safety & Control \\
\hline $25-29$ & $1.15(1.05,1.24)$ & $1.70(1.59,1.82)$ & $1.56(1.45,1.66)$ & $1.73(1.61,1.84)$ & $20.1(16.8,23.7)$ & $13.7(10.6,16.8)$ \\
\hline $30-34$ & $1.07(0.99,1.16)$ & $1.73(1.63,1.84)$ & $1.29(1.20,1.38)$ & $1.76(1.66,1.87)$ & $9.6(7.7,12.1)$ & $9.8(7.5,12.2)$ \\
\hline $35-39$ & $1.05(0.98,1.11)$ & $1.83(1.74,1.92)$ & $1.19(1.12,1.26)$ & $1.86(1.76,1.94)$ & $5.1(3.7,6.6)$ & $5.1(3.7,6.6)$ \\
\hline $40-49$ & $1.04(1.0,1.09)$ & $1.87(1.81,1.93)$ & $1.15(1.10,1.19)$ & $1.88(1.82,1.94)$ & $4.0(3.1,4.8)$ & $3.4(2.6,4.2)$ \\
\hline $50-65$ & $1.03(0.99,1.07)$ & $1.86(1.80,1.92)$ & $1.10(1.06,1.15)$ & $1.87(1.82,1.93)$ & $2.7(2.0,3.4)$ & $2.4(1.8,3.1)$ \\
\hline All & $1.05(1.03,1.08)$ & $1.83(1.80,1.87)$ & $1.19(1.16,1.21)$ & $1.85(1.81,1.88)$ & $5.6(5.0,6.2)$ & $4.8(4.3,5.3)$ \\
\hline
\end{tabular}

The purpose of the Safety arm was to monitor incident disease and provide an early indication of the effect of the extended screening interval in the Intervention arm. Previous cohort studies have indicated that the negative predictive value of the HPV test provides extended protection from disease development compared with cytology testing (Dillner et al, 2008; Arbyn et al, 2012). Thus screening protocols for HPV-based testing in Canada and elsewhere (Murphy et al, 2011; Australian Government, 2014) propose extended intervals for subsequent testing for those screening HPV negative compared with pre-existing protocols for cytology testing in the same jurisdictions. The inclusion of HPV as a co-test with cytology also led to increased interval recommendations in the United States (Saslow et al, 2012; Moyer and on behalf of the U.S. Preventive Services Task Force, 2012). The HPV FOCAL trial was established to examine the effect of extending the interval in British Columbia where screening with cytology was recommended on a biennial schedule at the time the trial commenced. The results presented align with findings from other trials in that increased rates of prevalent disease (CIN2+ and CIN3 + ) are observed at the initial screen in the HPV tested arms (Naucler et al, 2007; Kitchener et al, 2009; Ronco et al, 2010; Arbyn et al, 2012; Rijkaart et al, 2012a; Ronco et al, 2014).

One of the major advantages of HPV-based screening is the consistency of automated measurement, whereas cytology requires 
subjective interpretation. Variation in the sensitivity of cytology between jurisdictions has been shown to be considerable (Nanda et al, 2000) so that the results of any individual study comparing HPV and cytology screening will depend upon the quality of cytology interpretation. British Columbia has been conducting cervical screening for over 50 years (Boyes et al, 1982; Anderson et al, 1988; Morrison et al, 1996) and its screening program has utilised a single laboratory with a well-established quality control system. British Columbia has the lowest rate of invasive cervical cancer in Canada (Canadian Cancer Society's Advisory Committee on Cancer Statistics, 2013) and Canada is a low incidence jurisdiction globally (Arbyn et al, 2011). In the data presented, the detection rate ratio for cytology compared with HPV testing was $67 \%$ for the detection of CIN2 + in the first round. Planned screening with both LBC and HPV at 48 months in the Intervention and Control arms will provide further data on the longer-term effects in this population.

In this trial, cytology triage and follow-up testing at 12 months was used to manage HPV-positive women. Other algorithms are being considered (Rijkaart et al, 2012b; Australian Government, 2014; Wright et al, 2015; Wentzensen et al, 2016) and their utilisation will alter the overall efficacy of HPV-based screening and the demand it places on diagnostic services (Coldman et al, 2015). In the future it is likely that new management strategies of HPV-positives cases will result in improved disease detection and/or decreased resource use. Preventing cervical cancer is dependent not only on identification and treatment of pre-invasive disease but also on its earliest identification. Although two rounds of cytology resulted in similar levels of disease detection, some cases were detected later in the Control arm (24 months) so that the risk of invasive cancer will be lower in those screened with HPV as has been observed in other trials (Arbyn et al, 2012; Ronco et al, 2014). More definitive results of the relative effect of HPV screening at a lower frequency than LBC will be available from future analyses.

This study was conducted in women enrolled in the Cervical Screening Program in British Columbia residing in Vancouver or Victoria, who were patients of participating physicians and who provided informed consent. Participants were well educated (Ogilvie et al, 2010) and may be anticipated to have lower disease rates than the general population. Despite this, in Round 1, women randomised to the Control arm had rates of disease detection at least as high as that reported for the population (BC Cancer Agency, 2014). This may be related to the high rate of annual screening in the $\mathrm{BC}$ population (BC Cancer Agency, 2014) with over 30\% returning within 18 months of a previous negative screen. Twenty-four month return rates were lower for the Control than Safety arm despite double-blind screening allocation. This arose because of increased returns associated with higher baseline follow-up screening in the Safety arm and may also have been because this was the final study screen for that arm.

\section{CONCLUSION}

A single round of HPV-based screening was found to be as effective at detecting high-grade CIN as two rounds of LBC screening, and it appears that doubling the screening interval posed no risk to enrolled women. LBC testing at 24 months found less disease in those initially screened with HPV than those initially screened with LBC. Colposcopy utilisation for a single round of HPV screening was similar to two rounds of LBC screening.

\section{ACKNOWLEDGEMENTS}

The authors thank the BC Cervical Cancer Screening Program for providing the population data on colposcopic assessment in British
Columbia. This work was supported by the Canadian Institute for Health Research, Ottawa, Canada.

\section{CONFLICT OF INTEREST}

The authors declare no conflict of interest.

\section{REFERENCES}

Anderson GH, Boyes DA, Benedet JL, Le Riche JC, Matisic JP, Suen KC, Worth AJ, Millner A, Bennett OM (1988) Organisation and results of the cervical cytology screening programme in British Columbia, 1955-85. Br Med J (Clin Res Ed) 296(6627): 975-978.

Arbyn M, Ronco G, Anttila A, Meijer CJ, Poljak M, Ogilvie G, Koliopoulos G, Naucler P, Sankaranarayanan R, Peto J (2012) Evidence regarding human papillomavirus testing in secondary prevention of cervical cancer. Vaccine 30: F88-F99.

Arbyn M, Castellsague X, de Sanjose S, Bruni L, Saraiya M, Bray F, Ferlay J (2011) Worldwide burden of cervical cancer in 2008. Ann Oncol 22(12): 2675-2686.

Australian Government (2014) National Cervical Screening Program Renewal. Available at http://www.cancerscreening.gov.au/internet/screening/ publishing.nsf/Content/overview-of-the-renewal (Accessed on 19 August 2014).

BC Cancer Agency (2014) Cervical Cancer Screening Program 2013 Annual Report.

Boyes DA, Morrison B, Knox EG, Draper GJ, Miller AB (1982) A cohort study of cervical cancer screening in British Columbia. Clin Invest Med 5(1): $1-29$.

Breslow NE, Day NE (1980) Statistical methods in cancer research. Volume 1The analysis of case-control studies. IARC Scientific Publications: Lyon, France.

Canadian Cancer Society's Advisory Committee on Cancer Statistics (2013) Canadian Cancer Statistics 2013.

Coldman AJ, Phillips N, van Niekerk DJ, Smith LW, Krajden M, Cook DA, Quinlan DJ, Ehlen TG, Miller D, Stuart GC, Peacock SJ, Martin RE, Franco EL, Ogilvie GS (2015) Projected impact of HPV and LBC primary testing on rates of referral for colposcopy in a Canadian cervical cancer screening program. J Obstet Gynaecol Can 37(5): 412-420.

Cook DA, Mei W, Smith LW, van Niekerk DJ, Ceballos K, Franco EL, Coldman AJ, Ogilvie GS, Krajden M (2015) Comparison of the Roche cobas 4800 and Digene Hybrid Capture 2 HPV tests for primary cervical cancer screening in the HPV FOCAL trial. BMC Cancer 15(1): 968.

Cuzick J, Arbyn M, Sankaranarayanan R, Tsu V, Ronco G, Mayrand MH, Dillner J, Meijer CJ (2008) Overview of human papillomavirus-based and other novel options for cervical cancer screening in developed and developing countries. Vaccine 26(Suppl 10): K29-K41.

Cuzick J, Clavel C, Petry KU, Meijer CJ, Hoyer H, Ratnam S, Szarewski A, Birembaut P, Kulasingam S, Sasieni P, Iftner T (2006) Overview of the European and North American studies on HPV testing in primary cervical cancer screening. Int J Cancer 119(5): 1095-1101.

DeMets DL, Lan KKG (1995) Recent Advances in Clinical Trial Design and Analysis. In Thall PF (ed). Kluwer Academic Publishers: Massachusetts, USA.

Dillner J, Rebolj M, Birembaut P, Petry KU, Szarewski A, Munk C, de Sanjose S, Naucler P, Lloveras B, Kjaer S, Cuzick J, van Ballegooijen M, Clavel C, Iftner T. Joint European Cohort, S. (2008) Long term predictive values of cytology and human papillomavirus testing in cervical cancer screening: joint European cohort study. BMJ 337: a1754.

Franceschi S, Denny L, Irwin KL, Jeronimo J, Lopalco PL, Monsonego J, Peto J, Ronco G, Sasieni P, Wheeler CM (2011) Eurogin 2010 roadmap on cervical cancer prevention. Int J Cancer 128(12): 2765-2774.

Health Council of the Netherlands (2011) Population Screening for Cervical Cancer. Available at http://www.gezondheidsraad.nl/sites/default/files/ Summary_Population_screening_cervical_cancer.pdf (Accessed on 21 December 2013).

Kitchener HC, Almonte M, Thomson C, Wheeler P, Sargent A, Stoykova B, Gilham C, Baysson H, Roberts C, Dowie R, Desai M, Mather J, Bailey A, Turner A, Moss S, Peto J (2009) HPV testing in combination with liquidbased cytology in primary cervical screening (ARTISTIC): a randomised controlled trial. Lancet Oncol 10(7): 672-682. 
Leinonen MK, Nieminen P, Lonnberg S, Malila N, Hakama M, Pokhrel A, Laurila P, Tarkkanen J, Anttila A (2012) Detection rates of precancerous and cancerous cervical lesions within one screening round of primary human papillomavirus DNA testing: prospective randomised trial in Finland. BMJ 345: e7789.

Mayrand MH, Duarte-Franco E, Rodrigues I, Walter SD, Hanley J, Ferenczy A, Ratnam S, Coutlee F, Franco EL. Canadian cervical cancer screening trial study,group (2007) Human papillomavirus DNA versus papanicolaou screening tests for cervical cancer. N Engl J Med 357(16): 1579-1588.

Morrison BJ, Coldman AJ, Boyes DA, Anderson GH (1996) Forty years of repeated screening: the significance of carcinoma in situ. Br J Cancer 74(5): 814-819.

Moyer VA. on behalf of the US Preventive Services Task Force (2012) Screening for cervical cancer: US preventive services task force recommendation statement. Ann Intern Med 156(12): 880-891.

Murphy J, Kennedy E, Dunn S, Fung Kee Fung M, Gzik D, McLachlin CM, Shier M, Paszat L (2011) Cervical Screening: Guideline Recommendations. Available at https://www.cancercare.on.ca/common/pages/ UserFile.aspx?fileId=124511 (Accessed on: 19 December 2013).

Nanda K, McCrory DC, Myers ER, Bastian LA, Hasselblad V, Hickey JD, Matchar DB (2000) Accuracy of the Papanicolaou test in screening for and follow-up of cervical cytologic abnormalities: a systematic review. Ann Intern Med 132(10): 810-819.

Naucler P, Ryd W, Tornberg S, Strand A, Wadell G, Elfgren K, Radberg T, Strander B, Johansson B, Forslund O, Hansson BG, Rylander E, Dillner J (2007) Human papillomavirus and Papanicolaou tests to screen for cervical cancer. N Engl J Med 357(16): 1589-1597.

Ogilvie GS, Krajden M, van Niekerk DJ, Martin RE, Ehlen TG, Ceballos K, Smith LW, Kan L, Cook DA, Peacock S, Stuart GC, Franco EL, Coldman AJ (2012) Primary cervical cancer screening with HPV testing compared with liquid-based cytology: results of round 1 of a randomised controlled trial-the HPV FOCAL Study. Br J Cancer 107(12): 1917-1924.

Ogilvie GS, van Niekerk DJ, Krajden M, Martin RE, Ehlen TG, Ceballos K, Peacock SJ, Smith LW, Kan L, Cook DA, Mei W, Stuart GC, Franco EL, Coldman AJ (2010) A randomized controlled trial of human papillomavirus (HPV) testing for cervical cancer screening: trial design and preliminary results (HPV FOCAL Trial). BMC Cancer 10: 111.

Rijkaart DC, Berkhof J, Rozendaal L, van Kemenade FJ, Bulkmans NW, Heideman DA, Kenter GG, Cuzick J, Snijders PJ, Meijer CJ (2012a) Human papillomavirus testing for the detection of high-grade cervical intraepithelial neoplasia and cancer: final results of the POBASCAM randomised controlled trial. Lancet Oncol 13(1): 78-88.

Rijkaart DC, Berkhof J, van Kemenade FJ, Coupe VM, Hesselink AT, Rozendaal L, Heideman DA, Verheijen RH, Bulk S, Verweij WM,
Snijders PJ, Meijer CJ (2012b) Evaluation of 14 triage strategies for HPV DNA-positive women in population-based cervical screening. Int J Cancer 130(3): 602-610.

Ronco G, Dillner J, Elfström KM, Tunesi S, Snijders PJ, Arbyn M, Kitchener H, Segnan N, Gilham C, Giorgi-Rossi P (2014) Efficacy of HPV-based screening for prevention of invasive cervical cancer: follow-up of four European randomised controlled trials. Lancet 383(9916): 524-532.

Ronco G, Giorgi-Rossi P, Carozzi F, Confortini M, Dalla Palma P, Del Mistro A, Ghiringhello B, Girlando S, Gillio-Tos A, De Marco L (2010) Efficacy of human papillomavirus testing for the detection of invasive cervical cancers and cervical intraepithelial neoplasia: a randomised controlled trial. Lancet Oncol 11(3): 249-257.

Ronco G, Meijer CJ, Cuzick J, Giorgi-Rossi P, Peto J, Segnan N, Dillner J (2012) Screening for cervical cancer. Ann Internal Med 156(8): 604-605.

Sasieni P, Cuzick J (2002) Could HPV testing become the sole primary cervical screening test? J Med Screen 9(2): 49-51.

Saslow D, Solomon D, Lawson HW, Killackey M, Kulasingam SL, Cain JM, Garcia FA, Moriarty AT, Waxman AG, Wilbur DC, Wentzensen N, Downs Jr LS, Spitzer M, Moscicki AB, Franco EL, Stoler MH, Schiffman M, Castle PE, Myers ER, Chelmow D, Herzig A, Kim JJ, Kinney W, Herschel WL, Waldman J (2012) American Cancer Society, American Society for Colposcopy and Cervical Pathology, and American Society for Clinical Pathology screening guidelines for the prevention and early detection of cervical cancer. J Low Genit Tract Dis 16(3): 175-204.

van den Akker-van Marie ME, van Ballegooijen M, Rozendaal L, Meijer C.J.L.M., Habbema JD (2003) Extended duration of the detectable stage by adding HPV test in cervical cancer screening. Br J Cancer 89: 1830-1833.

Wentzensen N, Schiffman M, Palmer T, Arbyn M (2016) Triage of HPV positive women in cervical cancer screening. J Clin Virol 76: S49-S55.

Wright TC, Stoler MH, Behrens CM, Apple R, Derion T, Wright TL (2012) The ATHENA human papillomavirus study: design, methods, and baseline results. Am J Obstet Gynecol 206: 46.

Wright TC, Stoler MH, Behrens CM, Sharma A, Zhang G, Wright TL (2015) Primary cervical cancer screening with human pappillomavirus: End of study results from the Athena study using HPV as the first-line screening test. Gynecol Oncol 136: 189-197.

This work is published under the standard license to publish agreement. After 12 months the work will become freely available and the license terms will switch to a Creative Commons AttributionNonCommercial-Share Alike 4.0 Unported License. 